\title{
The visibility of agricultural subsidies and market illusions in the Common Agricultural Policy: Some evidence from farmers' views in Germany, Portugal and the United Kingdom
}

\author{
CARSTEN DAUGBJERG ${ }^{\mathrm{a}}$, RICHARD TRANTER $^{\mathrm{b}}$, PHILIP JONES $^{\mathrm{b}}$, \\ JONATHAN LITTLE ${ }^{\mathrm{b}}$, LEONARDO COSTA $^{\mathrm{c}}$, THOMAS KNAPP ${ }^{\mathrm{d}}$, \\ MIGUEL SOTTOMAYOR ${ }^{\mathrm{c}}$ \& ALAN SWINBANK ${ }^{\mathrm{b}}$ \\ ${ }^{\mathrm{a}}$ University of Aarhus, Denmark; ${ }^{\mathrm{b}}$ University of Reading, United Kingdom; ${ }^{\mathrm{c}}$ Portuguese \\ Catholic University, Portugal; ${ }^{\mathrm{d}}$ University of Göttingen, Germany
}

\begin{abstract}
This article demonstrates that the design and nature of agricultural support schemes has an influence on farmers' perception of their level of dependence on agricultural support. While direct aid payments inform farmers about the extent to which they are subsidised, indirect support mechanisms veil the level of subsidisation, and therefore they are not fully aware of the extent to which they are supported. To test this hypothesis, we applied data from a survey of 4,500 farmers in three countries: the United Kingdom, Germany and Portugal. It is demonstrated that indirect support, such as that provided through artificially high consumer prices, gives an illusion of free and competitive markets among farmers. This 'visibility' hypothesis is evaluated against an alternative hypothesis that assumes farmers have complete, or at least a fairly comprehensive level of, information on agricultural support schemes. Our findings show that this alternative hypothesis can be ruled out.
\end{abstract}

\section{Introduction}

In a context characterised by great social, political and economic complexity, people are likely to develop their perceptions on the basis of incomplete information. In forming their perceptions of public policies, they tend to rely strongly on the signals public policies send. Given these limitations on citizens' ability to understand public policies, the political process of designing these policies is a strategic act that aims at mobilising some segments of the public while keeping others passive. The use of specific policy instruments highlights some effects while blurring others, and this has very important political consequences even if citizens wrongly perceive policy. As Arnold (1990: 25) points out: 'Citizens may have imperfect understanding of cause and effect in the policy world. Nevertheless, their beliefs about cause and effect are important, for beliefs may affect ... their preferences about policy issues.' An important factor affecting citizens' perception of public policies is their degree 
of visibility. By hiding some effects of policies from the public, policy makers can, for instance, blur their apparent costs.

In agricultural policy studies, it has been assumed that the degree of visibility of a support mechanism plays an important role in influencing consumers' and taxpayers' attitudes to agricultural support. It is argued that the use of indirect (or low-visibility) farm support has the effect of politically pacifying consumers and taxpayers because they are not aware of the actual cost of that agricultural support. In the European Union (EU), farm subsidies are basically provided in two ways: either through direct aid payments to farmers (e.g., payments per hectare farmed) or through price support (i.e., keeping the prices received by farmers for their produce above world market prices - e.g., the EU price of sugar is three times as high as the world market price). Direct aid payments are funded from tax revenues, whereas in price support systems, consumers provide the bulk of the support to the farmer through paying artificially high food prices.

Direct support is much more visible to taxpayers than price support because the costs are clearly stated in public budgets. This makes it an easy target for those who oppose subsidising agriculture and farmers. Thus, it is often claimed that the farming lobby has a strong interest in designing agricultural support schemes in a way that hides the costs to consumers and taxpayers because it prevents them from questioning agricultural policy (see Roberts et al. 1999: 80; Kjeldahl 1994: 7; Rieger 2000: 198). There is some evidence that this reasoning can indeed be found among farm unions. The European association of farm unions, COPA, has expressed fears that farm interests would be vulnerable to a switch from price support to direct payments, arguing that: '[I]t is not certain that Community taxpayers will agree to shoulder the financial burden on a permanent and continuous basis' (COPA 1991: 3).

However, the assumption that agricultural support provided through public budgets is more vulnerable to political opposition is questioned by Coleman et al. (1997: 472) on the basis of experiences in the United States. Their scepticism stems from the fact that direct income support to American farmers was introduced in 1985, but it was not until 1996 that it became subject to political attack. However, comparative studies on the consequences of applying direct support payments to farmers are needed before any firm conclusions on the question can be drawn. Although policy feedback processes seem to gather increasing interest in explaining policy development over time (e.g., Thelen 1999; Pierson 2000), the phenomenon has rarely been studied in agriculture (for a rare and excellent study on policy feedback in agriculture, see Coleman \& Grant (1998), who analyse the feedback effect of agricultural finance policies on the liberalisation of agricultural credit systems in five countries). 
The assumed relationship between visibility of public policies and citizens' perception has been more systematically investigated in the area of taxation policy. For instance, Wilensky (1976) argued that the visibility of taxes is an important factor helping to explain tax backlashes, and Hansen (1983) maintained that politicians deliberately disguise taxes to reduce the risk of political opposition to taxation. An important research agenda in the study of taxation policy has been to establish whether tax systems characterised by a low degree of tax visibility provides fiscal illusions to a higher extent than those characterised by visible taxation. Fiscal illusion refers to 'a systematic misperception of fiscal parameters' (Oates 1991: 433; emphasis added). However, Oates' review shows that the research findings on the issue are inconclusive in part because studies of fiscal illusion use indirect measures to reveal the phenomenon. As Oates (1991: 433) says:

[T] he recent empirical literature on fiscal illusion has focused exclusively on the revenue side of the [public] budget; it consists of studies of tax and debt illusion. These studies search for evidence linking relatively hidden elements in the revenue structure to higher levels of taxes or spending. (see also Winter \& Mouritzen 2001: 111)

A much more reliable way to 'measure' fiscal illusion would be to undertake a survey among taxpayers to reveal their perception of taxation levels. While such studies of various types of fiscal illusions have been undertaken (e.g., Winter \& Mouritzen 2001; Sørensen 1992), the assumption of a relationship between visibility of taxes and citizens' perceptions of the taxes is weakly underpinned empirically. However, Blom-Hansen (2005) tests this assumption. He examined whether Danish renters suffer from fiscal illusion in relation to property taxation (renter illusion). To renters, property taxes are not visible because they are levied on the owner of the property, who passes them on to renters by including them in the rent. Blom-Hansen's survey shows that renters estimate the property tax rate less correctly than do property owners, but their estimations are not systematically biased, which is the defining criterion of the fiscal illusion hypothesis (see above). According to the renter illusion hypothesis, one would expect renters systematically to underestimate the tax rate, but they do not. Thus, the hypothesis is not supported by the findings.

Returning to the issue of the agricultural policy design's consequences for citizens' perceptions, we focus on the extent to which the policy design creates illusions among farmers. Agricultural policies providing support to farmers through artificially high consumer prices can be claimed to create a market illusion. Price support uses market mechanisms to allocate revenue, and this 
veils to many farmers the fact that they are subject to major income transfers from the rest of the society. Indeed, indirect support may very well give farmers the illusion that they operate in a free and competitive market (Daugbjerg 2003: 429). We adopt Blom-Hansen's (2005) research approach. We apply results from a survey to reveal the extent to which farmers suffer from market illusions. In the next section, we develop the hypotheses to be tested. Following this, the methodology employed to test the hypotheses is detailed. We go on to present the findings and, finally, draw conclusions.

\section{Hypotheses}

Even with the best of intentions, it may not be possible to take rational decisions because of a lack of complete information or because obtaining complete information may be a time-consuming task and require special skills. Moreover, in contrast to the market, where prices provide good guidelines to economic actors, politics 'lacks anything like the measuring rod of price' (Pierson 2000: 260); therefore, citizens use other sources of information when they acquire knowledge about public policies that affect them. In this process, the specific design of public policies becomes an important source of information influencing their perception of policy:

The specific design of programs may heighten the visibility of some social and political connections while obscuring others. In a context of great social complexity, policies may generate 'focusing events' or cues that help social actors to interpret the world around them. Policy induced cues may influence an individual's awareness of activity. (Pierson 1993: 619)

Citizens' awareness of policy effects may be based on an imperfect understanding of the way in which the policy produces its effects. For example, Arnold (1990:21) argues that people are more likely to understand the causal chain of single-stage policy instruments with immediate effects than that of multi-stage instruments with mediated effects because the policy mechanisms of the former tend to be more visible to them than those of the latter. In agricultural policy, it is much easier for farmers (and taxpayers as well) to detect the transfer effects of direct agricultural subsidies such as annual area payments than it is to discern the transfer effects of multi-stage policy instruments (e.g., indirect price support working through market management) even though the two support types have similar income effects. In the latter case, farmers may not realise the magnitude of agricultural support and its economic importance for them. Thus, 'visibility ... can vary independently of a 
policy's actual impact and ... this variation may be a product of policy design' (Pierson 1993: 622).

The EU's Common Agricultural Policy (CAP) has used two different approaches to boost farm incomes. Before the MacSharry reform of May 1992, most of the market regimes applied a high price model. These high prices were maintained by managing markets using import taxes, intervention purchases and export subsidies (with production often constrained by measures to control supply such as quotas). Through the increased prices they pay, consumers bear a major part of the cost of supporting farmers. This is true of the milk regime. The MacSharry reforms reduced intervention prices substantially in some sectors, and introduced direct payments to compensate farmers for the revenue loss. Thus cereal producers receive an area payment for the crops they grow; and beef producers receive a headage payment for the animals they keep. The so-called 'Agenda 2000' reform of March 1999 continued along this path by further reducing guaranteed prices and increasing direct payments. In practice, the two approaches are sometimes used at the same time within the same commodity regime (Swinbank 2002). The Fischler reforms, proposed initially in July 2002 and enacted in June 2003, have continued the reform process, but they came after the survey of farmers reported in this article.

The level of visibility of agricultural support in the two approaches outlined above is very different. Agricultural policies applying direct subsidy schemes clearly inform farmers (and the public) that they are the recipients of an income transfer from society. The magnitude of the individual payments is clearly seen by farmers when they receive the transfer (Kjeldahl 1994: 7), and they can easily calculate how dependent their income is upon agricultural subsidies; thus, direct payments can be said to have a high degree of visibility. As a result of being informed about the magnitude of support, farmers realise how dependent agriculture is on support.

Agricultural policies applying the high price model produce a market illusion among farmers, veiling the fact that they are, in fact, subject to major income transfers from the rest of society. Nevertheless, farmers may be aware of the actual benefits they receive from indirect and less visible payments. Following Arnold (1990: 29-30), who argues that information on the costs and benefits of policy is easily disseminated within national communities of citizens who have specialised communication networks maintained by interest associations, one could argue that information on support levels may be widely known among farmers. However, there are some facts that people do not want to know, especially if they contradict their core values (Pierson 2000: 260). Farmers may be uncomfortable with the fact that they are major recipients of public support, making them look like social security clients, and thus they may make no efforts to search for such information, nor may it be 
disseminated to them by their unions. Under such circumstances, the majority of farmers would have limited knowledge of their dependence on agricultural subsidies since the support model does not enable them to calculate the share of their gross receipts that can be put down to agricultural support. The market illusion created by price support may lead farmers to believe that agriculture is less dependent on agricultural support than it actually is.

The fact that the CAP market regimes vary in the way in which they subsidise farmers enables us to explore whether the degree of visibility of the support mechanisms affects farmers' perceptions of agriculture's dependence on farm subsidies. As a means of examining this issue, we present two hypotheses:

H1: Farmers receiving direct (i.e., visible) payments perceive dependence on agricultural support to be higher than those who farm under market regimes using indirect support measures, irrespective of the actual level of support.

HO: Perceived dependence on agricultural support is determined primarily by actual level of support.

The counter hypothesis $(\mathrm{HO})$ is based on a rational actor perspective in which farmers are assumed to possess complete, or at least fairly comprehensive, information on the regulatory environment within which they conduct their enterprise and thus understand the true nature of their support. Consequently, we would expect those farmers who are the most dependent on agricultural subsidies to be those who are most supportive of the CAP. Farmers' actual dependence on subsidies is assumed to equate to the level of support received by farmers within each of the market regimes. The actual level of support is measured by the Producer Support Estimate (PSE), which expresses the share of farmers' gross farm receipts that can be attributed to direct or indirect support (OECD 2002: 236; Legg 2003). This level varies significantly across market regimes.

\section{Methodology}

Evidence to test the two propositions or hypotheses was derived from a threecountry (Germany, Portugal and the United Kingdom) postal survey of farmers carried out during the autumn and winter of 2001-2002, as part of a research project looking at the acceptability of the introduction of a Bond Scheme as part of CAP reform (Swinbank \& Tranter 2004). The survey used an identical four-page questionnaire sent to 4,500 farmers in each of three 
countries. The sample was drawn from the Yellow Pages telephone book for the United Kingdom, pension records for Germany and the list of farmers from the Office of National Statistics for Portugal. When tested for representativeness, it was discovered that those with larger farm businesses were somewhat over-represented in each of the three countries. The response rate following two reminders was 40.2 per cent for the United Kingdom, 36.8 per cent for Germany and 33.4 per cent for Portugal. Tests for non-response bias were carried out in each country. Only two significant differences were found: the responses were biased towards older farmers in Portugal, and towards better-educated farmers in the United Kingdom.

On the survey questionnaire, farmers were asked to indicate their main type of farming activity by choosing from one of nine fixed categories. They were also asked to give their cropping and grass areas and livestock numbers. From this information, it was possible to assign farmers to the CAP commodity market regime in which they were predominately operating. However, this categorisation was not perfectly defined as many farmers operate under more than one market regime and thus may receive both direct and indirect support from the EU. For example, a farm that is predominately dairy may also grow cereals or maize for cattle feed and have a number of sheep and/or beef cattle. Thus, the farm business operates under three CAP commodity market regimes.

While a considerable number of arable farmers in the survey sample do not keep livestock and therefore only operate under the arable market regimes (all of which use direct payments), there are very few dairy farmers who only have one farming activity and thus operate under only one commodity market regime. Thus, say, dairy farmers' perceived dependence on agricultural support which, on the basis of the limited visibility of that support, one would expect to be lower than that of arable farmers, may be distorted by the fact that they also receive direct payments under other market regimes to which they are eligible. Despite this acknowledged overlapping of farms across multiple commodity regimes, it is hoped that any disturbance is minimised by the fact that the farmers were asked to categorise themselves on the survey questionnaire based on their own perceptions of farm type. Further clarity in the distinction between farm type categories was obtained by excluding from the analysis all farmers who described their enterprises as being 'mixed livestock and arable'. However, in interpreting the findings, we must still be aware that the 'noise' introduced by these overlaps might be expected to reduce the significance of group differences.

For the purpose of this analysis, four farm types were selected (see Table 1): dairy, cereals, pig and beef/sheep farms. Beef and sheep farming was listed as one category on the questionnaire because many farmers have both sheep 
Table 1. Number of sample farms in each of the key farm types in each country

\begin{tabular}{lccccc}
\hline Type of farming & $\begin{array}{c}\text { United } \\
\text { Kingdom }\end{array}$ & Germany & Portugal & $\begin{array}{c}\text { Combined } \\
\text { countries } \\
\text { dataset }\end{array}$ & $\begin{array}{c}\text { Percentage } \\
\text { of total }\end{array}$ \\
\hline Milk & 330 & 83 & 77 & 490 & 24.7 \\
Cereals & 140 & 286 & 231 & 657 & 33.1 \\
Beef, veal and & 509 & 95 & 150 & 754 & 38.0 \\
$\quad$ sheep meat & 13 & 48 & 22 & 83 & 4.2 \\
Pigs & 992 & 512 & 480 & 1,984 & 100.0 \\
Total & & & & & \\
\hline
\end{tabular}

and beef cattle enterprises and these operate under very similar policy regimes; they both apply direct payments in the form of payment per head of animal (often known as 'headage payment'), and the level of subsidy is high. Therefore, it did not make sense to treat these enterprises separately. Table 1 shows that this sub-sample consisted of a little under 2,000 farmers over the three countries. Of the total number of farms, 25 per cent were predominantly dairy, 33 per cent cereals, and nearly 40 per cent veal/beef and lamb/mutton. A little more than 4 per cent were pig producers. These four broad farm types were selected for analysis because they operate under four different commodity regimes that vary in terms of their degree of visibility and support level (as measured by the OECD's PSE). (Table 3 below shows how these four main commodity regimes differ on the two main dimensions of level of support and its visibility.)

Farmers in the sample were presented with three statements they were asked to rank according to the extent to which they were in agreement: 'The future of farming is dependent on continued support' (S1); 'If current support is withdrawn, many farms would become unprofitable' (S2); and 'Support for agricultural production should be phased out gradually' (S3). The three responses to these statements were used as indicators of the degree to which farmers believed agriculture is dependent on support. A five-point Likert scale was used in each case, with scores ranging from 5 ('Strongly agree') to 1 ('Strongly disagree'). For the purpose of this analysis, responses to these three statements were averaged to yield a single overall measure (or score) for each farmer showing the extent to which they believe that agriculture is dependent on support. Agreement with $S 1$ and $S 2$ is taken to reflect affirmation of a dependence on support. Agreement with $S 3$ is taken to reflect denial of a dependence on support. In constructing the composite variable, therefore, the five-point scale for $S 3$ was inverted before combining with $S 1$ and $S 2$. 
Table 2. An analysis of the level of correlation between the respondents' levels of agreement on statements related to support for farming

\begin{tabular}{lccc}
\hline & $(\mathrm{S} 1)$ & $(\mathrm{S} 2)$ & $(\mathrm{S} 3)$ \\
\hline $\begin{array}{c}\text { (S1) 'The future of farming is } \\
\text { dependent on continued } \\
\text { support.' }\end{array}$ & & 0.43985 & -0.45483 \\
$\begin{array}{l}\text { (S2) 'If current support is } \\
\text { withdrawn, many farms } \\
\text { would become unprofitable.' }\end{array}$ & $(\mathrm{P}<0.0001)$ & $(\mathrm{P}<0.0001)$ \\
$\begin{array}{c}\text { (S3) 'Support for agricultural } \\
\text { production should be } \\
\text { phased out gradually.' }\end{array}$ & $\begin{array}{c}0.43985 \\
(\mathrm{P}<0.00001)\end{array}$ & $\begin{array}{c}(\mathrm{P}<0.24642 \\
(\mathrm{P}<0.0001)\end{array}$ & \\
\hline
\end{tabular}

The results (presented in Table 2) show a strong positive correlation between $S 1$ and $S 2$ with a coefficient of 0.44 using a Spearman's correlation test. A priori, it would be expected that $S 3$ would correlate negatively with $S 1$ and $S 2$, and this is what is actually found: $S 3$ correlates with $S 1$ at -0.45 and with $S 2$ at -0.25 . All these correlations are statistically significant at the 0.1 per cent level. These correlation coefficients were also consistently replicated in the data for the individual study countries. From this it can be assumed that the three variables/statements do combine to form a meaningful and coherent construct reflecting perceived dependence of agriculture in general on support.

It is assumed that farmers' personal experiences with the support schemes of the CAP to a considerable extent form their degree of agreement on the general statements on the dependence on agricultural support. Of course, this assumption can be questioned, but more specific statements relating to farmers' own situations may cause other types of problems because they might actually measure the influence of other factors, such as farm management skills and levels of farm debt, on the perception of farmers. Whether or not our assumption is realistic will in fact be shown in the test of the visibility hypothesis. If the hypothesis is supported by the data, it can be concluded that the assumption upon which the hypothesis rests is valid.

\section{The findings}

The scores in the right-hand columns of Table 3 show the extent to which respondents agreed with statements relating to the dependence of farming on support. The findings presented in Table 3 show that the sample farmers, as a 
Table 3. Farmers' perceived dependence on support compared with the level and visibility of support

\begin{tabular}{|c|c|c|c|c|c|}
\hline Type of farming & $\begin{array}{l}\text { PSE (\%) for EU } \\
\quad(1999-2001)\end{array}$ & $\begin{array}{l}\text { Classification of } \\
\text { level of support } \\
\text { based on PSE }\end{array}$ & $\begin{array}{l}\text { Visibility of } \\
\text { support }\end{array}$ & $\begin{array}{l}\text { Measure of the degree } \\
\text { of perceived } \\
\text { dependence on support }{ }^{2}\end{array}$ & $\begin{array}{l}\text { Standard deviation of } \\
\text { perceived dependence } \\
\text { scores }\end{array}$ \\
\hline Milk & 45 & Medium & Low & 3.67 & 0.83 \\
\hline Cereals & 48 & Medium & High & 4.07 & 0.84 \\
\hline $\begin{array}{l}\text { Beef, veal and } \\
\text { sheep meat }\end{array}$ & $\begin{array}{l}\text { Beef: } 84 / \text { Sheep } \\
\text { meat: } 61\end{array}$ & High & High & 4.09 & 0.80 \\
\hline Pigs & 25 & Low & Low & 3.77 & 0.96 \\
\hline All commodities & 36 & - & - & 3.96 & 0.85 \\
\hline
\end{tabular}

Notes: ${ }^{1}$ PSE $\leq 25=$ low, $25<$ PSE $\leq 50=$ medium, PSE $>50=$ high. ${ }^{2}$ Maximum score was 5 .

Source for PSE estimates: OECD $(2002,2003)$. 
group, are in strong agreement that farming is dependent on support, although there is some measure of variation between farm types; the lowest average score (Milk) is 3.67 out of a possible maximum of 5 .

A statistical test was carried out in the form of a general linear model (GLM) to identify those variables with significant influence on perceived dependence on support (the dependent variable, DV). A GLM was chosen to permit categorical independent variables (IV) to be fitted by the use of dummy variables. These categorical variables were: the case study country, fulltime/part-time farming, level of education, and the farm's current business position. Under ideal circumstances, all of these variables would have been included in a single GLM, together with the key variables associated with the two hypotheses (HO: support level and $H 1$ : visibility), so that the relative importance of each in influencing perceived level of dependence could be determined. However, for statistical reasons, this could not be done. As both level of support and visibility are determined by product regime (represented in this case by the variable farm type), they have a common source of variance, and thus the two variables are statistically correlated. In order to avoid this multi-collinearity problem, it was necessary to gauge the explanatory power of the two variables in a less direct manner.

Three separate GLM models were run sharing a common dependent variable (perceived dependence on support - details available from the authors on request). To equation $H 0$ was added the IV, support level; to equation $H 1$ was added visibility; and to equation $H C$ was added the variable farm type all other IVs were shared in common (equation $H C$ in this case acted as a control). Because both support level and visibility are products of farm type, it is considered to be the best explanatory variable in respect of perceived dependence. Because all other explanatory factors are controlled, the statistical model ( $\mathrm{HO}$ or $\mathrm{H1}$ ) that comes closest to matching the model $\mathrm{R}^{2}$ of $H C$ can be assumed to contain the better determinant of perceived dependence on support.

Study of the residual errors of the three equations revealed rather skewed underlying distributions. This in part explains the rather low model $\mathrm{R}^{2}$ values

Table 4. $\mathrm{R}^{2}$ values for three near identical GLM models, varying a single parameter in each case

\begin{tabular}{lc}
\hline Model & $\mathrm{R}^{2}$ \\
\hline$H C$ & 0.097 \\
$H O$ & 0.081 \\
$H 1$ & 0.096 \\
\hline
\end{tabular}


that were derived. The application of power terms to the dependent variable was tested, but found not to improve model $R^{2}$ values significantly $\left(R^{2}\right.$ values for the three models are shown in Table 4).

The $\mathrm{R}^{2}$ value for model $H 1$ is much closer to the control than $H 0$, suggesting that visibility is a better determinant of perceived dependence on support than actual support level. The statistical significance of these differences is confirmed by an F-test comparing the model sum of squares of $H O$ and $H 1$ against $H C$ in turn (see Table 5; details of the full models involved in each case and the resulting coefficients are available from the authors on request). No significant difference is found between the model sum of squares (SS) of $H C$ and $H 1$ ( $\mathrm{p}>0.05$ ), while a very significant difference is found between the SS of $H C$ and $H O$.

The correspondence between the sum of squares for model H1 (containing the visibility variable) and model $H C$ (containing farm type) is key to the resolution of the hypotheses. This result leads to the conclusion that visibility of support is a better determinant of perception of dependency on support than level of support. Having determined the importance of these two sources of variation relative to each other, the next question is: How important is visibility in absolute terms? The parameter estimates of the $H 1$ model show that the move from a low-visibility commodity support regime to a high-visibility one results in a 0.349 increase in perceived dependency on support, with a confidence interval of 0.265 to 0.433 . The $H 1$ model $\mathrm{R}^{2}$ value also provides some guide, as it tells us that all of the IVs in the model, taken together, account for just 10 per cent of the variation in the DV. Assuming that all confounding factors have been eliminated (more discussion of this below) and that this is an accurate reflection of the impact of these variables, this suggests that

Table 5. F-tests of the significance of differences in pairs of sum of squares (SS) values (i.e., $\mathrm{HO}$ with $H C ; H 1$ with $H C$ )

\begin{tabular}{lcc}
\hline & df & SS \\
\hline H1 (visibility) & 1782 & 1137.935 \\
HC & 1780 & 1136.371 \\
\hline $\mathrm{F}=1.2257 ; \mathrm{p}=0.2938$. & & \\
\hline & df & SS \\
\hline H0 (support level) & 1781 & 1156.654 \\
HC & 1780 & 1136.371 \\
\hline
\end{tabular}

$\mathrm{F}=31.7915 ; \mathrm{p}=0.0000$. 
visibility is, in global terms, playing only a minor role in determining farmers' perception of the level of dependence on support in agriculture.

The relatively low model $\mathrm{R}^{2}$ values obtained in this analysis merit some discussion and explanation. Model $H 1$ accounts for just 10 per cent of the variance of the dependent variable. Power term transformation of the dependent variable yields little improvement. It is difficult to conceive of explanatory variables omitted from the analysis that might account for the remaining 90 per cent of variance as a large number of classificatory variables were tested before arriving at the subset used in the models reported here. Under these circumstances, the only reasonable course is to assume that the observed low $\mathrm{R}^{2}$ values (something that is not uncommon when using survey data of this kind) are due to low variation between groups, at least in terms of the DV.

It is certainly the case that standard deviation scores are both low for all farm types (with a whole sample average variance of just 25 per cent) and highly consistent between farm types (see Table 3 ). This might have a number of causes. For example, a collective dependency perception may have developed across all of EU agriculture, resulting perhaps from the high degree of regulation experienced by EU farmers and the very visible nature of the debate about the CAP. It is also probable that variation between commodity regimes is being eroded by the fact that farmers (in particular, those having livestock) operate under more than one CAP market regime. This is particularly problematic when analysing dairy farmers' perceptions because many of them also receive direct crop and/or beef payments and thus receive part of their support in a highly visible manner.

An additional cause of low $\mathrm{R}^{2}$ scores relates to a degree of collinearity between the two key explanatory variables (i.e., support level and visibility). It is apparent looking at Table 3 that in the cases of two of the four commodity regimes (i.e., pigs and beef/sheep/veal), these two variables co-vary (i.e., where one is 'high' the other is also 'high'). For data observations in these two commodity classes, there is no statistical basis to judge between the two variables. Removing data for these two commodity regimes increases the $H 1$ model $\mathrm{R}^{2}$ to 11.3 per cent.

The conclusion reached above arising out of the GLM analysis - that visibility is a better determinant of perceived dependence on support than actual support level - is further confirmed and developed by paired comparisons of the dependence scores obtained for each commodity regime (i.e., farm type). With each of these comparisons, the null hypothesis is the expected outcome based on support level. For example, in comparing milk with cereals, as the level of support in each case is classified as 'Medium', the null hypothesis is that there is no significant difference between the perceived dependence on support between the two groups. The information contained in the 
Table 6. Comparison of dependence scores between commodity regimes, together with predicted outcomes based on $\mathrm{HO}$ and $\mathrm{H} 1$

\begin{tabular}{|c|c|c|c|c|}
\hline \multirow[b]{2}{*}{$\begin{array}{l}\text { Farm type } \\
\text { comparison }\end{array}$} & \multirow[b]{2}{*}{$\begin{array}{c}\text { Mean } \\
\text { difference }\end{array}$} & \multicolumn{2}{|c|}{ Predicted outcome } & \multirow[b]{2}{*}{ Actual result } \\
\hline & & $\begin{array}{c}\text { Visibility } \\
\text { hypothesis (H1) }\end{array}$ & $\begin{array}{c}\text { Support level } \\
\text { hypothesis (H0) }\end{array}$ & \\
\hline Milk - Cereals & -0.39 & $\mathrm{~S}$ & NS & $\begin{array}{c}\mathrm{S} \\
(\mathrm{p}=0.000)\end{array}$ \\
\hline Milk - Pigmeat & -0.09 & NS & S & $\begin{array}{c}\text { NS } \\
(p=0.775)\end{array}$ \\
\hline$(\mathrm{B}, \mathrm{V}, \mathrm{S})$ - Pigmeat & 0.32 & S & $S$ & $\begin{array}{c}S \\
(p=0.006)\end{array}$ \\
\hline Cereals - Pigmeat & 0.30 & S & S & $\begin{array}{c}\mathrm{S} \\
(\mathrm{p}=0.012)\end{array}$ \\
\hline Milk - $(\mathrm{B}, \mathrm{V}, \mathrm{S})$ & -0.41 & $\mathrm{~S}$ & $S$ & $\begin{array}{c}\mathrm{S} \\
(\mathrm{p}=0.000)\end{array}$ \\
\hline$(\mathrm{B}, \mathrm{V}, \mathrm{S})$ - Cereals & 0.02 & NS & $S$ & $\begin{array}{c}\mathrm{NS} \\
(\mathrm{p}=0.972)\end{array}$ \\
\hline
\end{tabular}

Notes: $(\mathrm{B}, \mathrm{V}, \mathrm{S})$ is a combined category for beef, veal and sheep meat; NS = not significant; $\mathrm{S}=$ significant.

support-level variable therefore provides for a series of one-tailed null hypotheses, which, as the data are present at the ordinal level of measurement, are most appropriately analysed by the powerful non-parametric Mann Whitney $U$ test. The results of these comparisons are shown in Table 6 .

These tests again support the hypothesis on the primacy of visibility over support level. This is particularly evident looking at the comparison of milk with cereals. Both regimes are supported at roughly the same level (PSE percentage of 45 and 48, respectively). Dairy farmers are the group who felt least dependent on support (a mean score of 3.67), while cereal farmers felt more dependent on subsidies (a mean score of 4.07). As can be seen in Table 6 , the difference between these scores is statistically significant, indicating that the low visibility of this support has influenced dairy farmers' perception on the extent to which agriculture is dependent upon it.

Comparing the perceptions of pig and dairy farmers also supports the visibility hypothesis as the difference in perceptions is not statistically significant despite the fact the support levels are very different. As Table 3 shows, the PSE for pigs is 25 per cent, while it is 45 per cent for milk. Had differences in support level had explanatory value as $\mathrm{HO}$ suggests, then the difference in perception should have been statistically significant, which it is not. Indeed, the 
difference in perception should have been rather large. Comparing the perceptions of pig producers with those of beef/sheep farmers further weakens HO. Although these two groups of farmers are at the opposite ends of the support scale (PSE percentage for pigs is 25 and $84 / 61$ for beef/sheep), the difference in perceptions is not as large as $\mathrm{HO}$ suggests it should be. The comparison between cereals and pig farmers does not enable us to establish which hypothesis is supported by the data in this particular comparison since both predict a statistically significant difference in perceptions, which is the actual result.

There is also a statistically significant difference between dairy farmers' and beef/sheep farmers' perceptions. However, it is not possible to tell whether this is due to differences in visibility or support level. As Table 3 shows, support to dairy farmers is at a medium level (PSE $=45$ per cent), while the level of support to beef/sheep farmers is high ( $\mathrm{PSE}=84 / 61$ per cent). This means that the difference in support level might explain the difference in perception. However, when we compare the perceptions of the highly supported beef/sheep farmers with that of the medium supported cereal farmers, we find no statistically significant difference. Since the market regimes these two groups of farmers operate under have highly visible support measures, we must conclude that it is the similar degree of visibility that explains the similarity in perceptions on support dependence.

\section{Concluding comments}

Our analysis shows that there is clear evidence that the visibility of agricultural subsidies affects how farmers perceive agriculture's dependence on support, albeit at a modest level. Farmers receiving direct aid payments, which are a highly visible means of agricultural support, were more likely to state that agriculture was dependent on support than were farmers receiving price support, which is indirect and thus a less visible support measure. The results of our analysis provide no support for the notion that actual support levels influence farmers' perception of dependence on agricultural support (i.e., variation in the support level across agricultural commodity groups cannot explain variation in perceptions). For this reason, farmers cannot be said to be rational actors, possessing full information on the regulatory context in which they conduct their farming activity. Instead, their perceptions are influenced by the signals sent through policy design. Since farmers operating predominately under commodity market regimes applying indirect support tend to believe that they are less dependent on agricultural support than those receiving direct support, the CAP does indeed generate market illusions 
among some farmers. Thus, farmers' perceptions are influenced by the signals that the design of agricultural policy measures brings about. Since we found that farmers being supported in less visible ways were more likely to state that they were less dependent on agricultural support than those receiving support by highly visible means, we have a strong case for arguing that illusions may be present in many other types of public policies using less visible policy instruments.

The MacSharry reforms of the CAP in 1992 cut support prices and introduced direct payments for each hectare of eligible crops sown and each eligible livestock unit kept to compensate farmers for the price reductions. This resulted in a significant increase in the visibility of agricultural support, and may have had implications for subsequent agricultural policy reform in the EU. The Fischler reforms adopted in June 2003 decoupled direct aid payments from any production requirement with the introduction of the Single Payment Scheme, established on the basis of a farmer's prior claims for area and headage payments. The resistance to the Fischler reforms was significantly lower within the farming community and among farm ministers than was the resistance to the transformation from price support into direct support in the MacSharry reforms of 1992.

Elaborating on our findings, we suggest that an important, but not sole, reason why European farmers were less opposed to the Fischler reforms of 2003 than they were to the MacSharry reforms of 1992 was the fact that the introduction of direct payments in 1992 made many farmers aware that they were subject to major income transfers from the rest of the society - a situation many of them felt was at odds with their perception of themselves as self-employed people. The Fischler reforms decoupled direct payments from production inputs, but made them conditional on compliance with environmental, animal health and welfare, and food safety regulations and standards (cross-compliance). This redefinition of direct support from being a compensation payment for price cuts into a payment for non-marketable goods and services provided to society by farmers may be more attractive than receiving the direct aid payments introduced in the MacSharry reforms.

In 1992, farm leaders said that the switch from price support to direct support made the CAP look like a social policy (Daugbjerg 2003: 429), which was regarded as highly undesirable within the farming community and caused strong opposition to the 1992 reforms. The redefinition of direct support as a payment for services to society may make future efforts to reduce or dismantle direct payments more difficult. Farmers would then feel that they would be losing payment for their 'produce'. This might mobilise significant resistance within the farming community, perhaps precluding support reductions. 


\section{Acknowledgments}

This article is a revised version of a paper presented at the 80th EAAE Seminar, 'New Policies and Institutions for European Agriculture', University of Ghent, 24-26 September 2003. We are grateful for the comments received at that seminar and also give thanks to Jens Blom-Hansen, Viola Burau and three anonymous referees. Thanks are also due to Howard Gruff and Mike Patefield of the School of Applied Statistics of the University of Reading for statistical advice. The article uses data derived from a research project ('An assessment of the practicalities and acceptability of a bond scheme as part of Common Agricultural Policy reform - QLRT-1999-01510') financed under the Fifth Framework Research Programme of the European Commission and involving partners at the Centre for Agricultural Strategy of the University of Reading, the Institute of Agricultural Economics at Georg-August Universität, Göttingen, and the Faculty of Economics and Management at the Portuguese Catholic University, Porto. The financial support of the European Commission and the Aarhus University Research Foundation is much appreciated.

\section{References}

Arnold, R.D. (1990). The logic of congressional action. New Haven, CT: Yale University Press.

Blom-Hansen, J. (2005). Renter illusion: Fact or fiction. Urban Studies 42: 127-140.

Coleman, W.D. \& Grant, W.P. (1998). Policy convergence and policy feedback: Agricultural finance policies in a globalizing era. European Journal of Political Research 34: 225-247.

Coleman, W.D., Atkinson, M.M. \& Montpetit, É. (1997). Against the odds: Retrenchment in agriculture in France and the United States. World Politics 49: 453-481.

COPA (1991). COPA Proposal on the Future of the Common Agricultural Policy (CAP), 23 May 1991, Pr (91) 13. Brussels: COPA.

Daugbjerg, C. (2003). Policy feedback and paradigm shift in EU agricultural policy: The effects of the MacSharry reform on future reform. Journal of European Public Policy 10: 421-437.

Hansen, S.B. (1983). The politics of taxation: Revenue without representation. New York: Praeger.

Kjeldahl, R. (1994). Reforming the reform? The CAP at a watershed. In R. Kjeldahl \& M. Tracy (eds), Renationalisation of the Common Agricultural Policy. Valby/la Hutte: Institute of Agricultural Economics/Agricultural Policy Studies, pp. 5-22.

Legg, W. (2003). Agricultural subsidies: Measurement and use in policy evaluation. Journal of Agricultural Economics 54: 175-201.

Organisation for Economic Cooperation and Development (OECD) (2002). Agricultural policies in OECD countries: Monitoring and evaluation. Paris: OECD. 
Organisation for Economic Cooperation and Development (OECD) (2003). Agricultural policies in OECD countries: Monitoring and evaluation. Paris: OECD.

Oates, W.E. (1991). On the nature and measurement of fiscal illusion: A survey. In W.E. Oates (ed.), Studies in fiscal federalism. Worcester, MA: Edward Elgar, pp. 431-448.

Pierson, P. (1993). When effect becomes cause: Policy feedback and political change. World Politics 45: 595-628.

Pierson, P. (2000). Increasing returns, path dependence and the study of politics. American Political Science Review 94: 251-267.

Rieger, E. (2000). The Common Agricultural Policy: Politics against markets. In H. Wallace $\&$ W. Wallace (eds), Policy-making in the European Union, 4th edn. Oxford: Oxford University Press, pp. 179-210.

Roberts, I. et al. (1999). Reforming world agricultural trade policies (ABARE Research Report 99.12). Canberra: Australian Bureau of Agricultural and Resource Economics.

Sørensen, R. (1992). Fiscal illusions: Nothing but illusions. European Journal of Political Research 22: 279-305.

Swinbank, A. (2002). The Common Agricultural Policy. In J. Gower (ed.), The European Union handbook, 2nd edn. London/Chicago, IL: Fitzroy Dearborn, pp. 164-175.

Swinbank, A. \& Tranter, R.B. (eds) (2004). A bond scheme for Common Agricultural Policy reform. Wallingford: CABI.

Thelen, K. (1999). Historical institutionalism in comparative politics. Annual Review of Political Science 2: 369-404.

Wilensky, H.L. (1976). The 'new corporatism', centralization and the welfare state. London: Sage.

Winter, S. \& Mouritzen, P.E. (2001). Why people want something for nothing: The role of asymmetrical illusions. European Journal of Political Research 39: 109-143.

Address for correspondence: Carsten Daugbjerg, Department of Political Science, University of Aarhus, Universitetsparken, DK-8000 Aarhus C, Denmark

Tel.: +45 894212 83; Fax: +45 861398 39; E-mail: cd@ps.au.dk 